Vorläufige Noliz über die Einwirkung von salpetriger Säure auf Amidinitro- und Aminitrophenylsäure;

\title{
von Peter Griefs.
}

Wird in eine alkoholische Lösung von Amidinitrophenylsäure $\left(\mathrm{C}_{12}\left(\begin{array}{c}\mathrm{H}_{2} \\ 2 \\ \mathrm{NO}_{4} \\ \mathrm{H}_{2} \mathrm{~N}\end{array}\right) \mathrm{HO}\right)$ ein rascher Strom von salpetriger Säure geleitet, so fällt, nachdem die Einwirkung längere Zeit angedauert hat, ein Körper in messinggelben Schuppen nieder. Dieser läfst sich leicht durch Umkrystallisiren aus Alkohol reinigen. Die Mullerlauge, aus welcher der Körper sich abschied, enthält Dinitrophenylsäure. Ich glaubte, der neue Körper würde seiner Bildungsweise gemäls die Zusam-

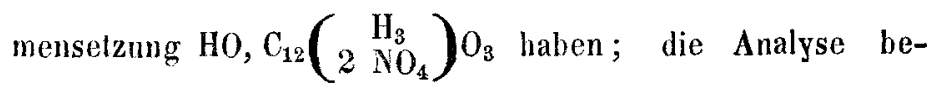
lehrle mich jedoch, dafs sich seine Zusammensetzung durch die empirische Formel :

$$
\mathrm{C}_{12} \mathrm{H}_{2} \mathrm{~N}_{4} \mathrm{O}_{10}
$$

ausdruicken läst. Die Verbrennung des bei $100^{\circ}$ getrockneten Körpers gab im Mitlel :

$\begin{array}{lr}\text { C } & 34,2 \\ \text { H } & 1,1,\end{array}$

die obige Formel verlangt :

$$
\begin{array}{ll}
\mathrm{C} & 34,3 \\
\mathrm{H} & 0,9 \mathrm{pC} .
\end{array}
$$

Die nach Bunsen's Methode ausgeführte Stickstoffbestimmung ergab das Verhältnifs des Stickstoffs zum Koh- 


\section{Griefs, vorläufige Notiz über die Einwirkung von}

lenstoff $=\frac{1}{3}$. Diese neue Substanz hat durchaus nicht den Character einer Säure. Mit Alkalien zerfällt sie unter Gasentwickelung in Dinitrophenylsäure.

Die von La arent und Gerhardt dargestellte Aminitrophenylsäure $\mathrm{HO}, \mathrm{C}_{12}\left(\begin{array}{c}\mathrm{H}_{3} \\ \mathrm{NO}_{4} \\ \mathrm{H}_{2} \mathrm{~N}\end{array}\right) 0$ erleidet durch salpetrige Säure eine ähnliche Zersetzung. Es bildet sich ein gelber krystallinischer Körper, dessen Zusammenselzung sich durch die Formel :

$$
\mathrm{C}_{12} \mathrm{H}_{3} \mathrm{~N}_{3} \mathrm{O}_{6}+\mathrm{HO}
$$

ausdrücken läfst. Die Verbrennung des über $\mathrm{SO}_{3}$ getrockneten Körpers ergab :

$$
\begin{array}{rr}
\text { C } & 41,5 \\
\text { I } & 2,4 .
\end{array}
$$

Diese Zahlen entsprechen der angeführlen Formel, welche verlangt :

$$
\begin{array}{lr}
\mathrm{C} & 41,4 \\
\mathrm{H} & 2,3 .
\end{array}
$$

Das Verhältnifs des $\mathrm{N}$ zum $\mathrm{C}$ ergab sich $=\frac{1}{4}$.

Dieser Körper erträgt nicht die Hilze des Wasserbades, sondern zersetzt sich durch dieselbe unter heftiger Explosion. Alkalien lösen ihn unter Gascntwickelung mit rother Farbe, wohei er möglicherweise in Nitrophenylsäure übergeführt wird.

Ich habe auch noch Brom und Untersalpetersäure und Chlor und Untersalpetersäure enthaltende Aminsäuren der Phenylsäure dargestellt und diese mit $\mathrm{NO}_{3}$ behandelt. Diese geben, wie es scheint, ähnliche Zerselzungsproducte.

Die Bildungsweise, Eigenschaften und eigenthümliche $\mathrm{Zu}-$ sammensetzung dieser liörper verleihen, wie ich glaube, den- 
salpetriger Säure auf Amidinitro- u. Aminitrophenylsäure. 125

selben einiges Interesse. Ich enthalte mich übrigens, ehe ich ihre Zersetzungsproducte genauer kenne, mit deren Studium ich schon seit längerer Zeit in Laboralorium des Hrn. Prof. Kolbe beschäftigt bin, jedes Urtheils über ihre rationelle Constilution, hoffe jedoch in kurzer Zeit Mittheilungen über dieselbe machen zu können.

Ueber ein einfaches Verfahren, unreines Wasserstoffgas und kohlensaures Gas geruchlos zu machen;

von J. Stenhouse.

Wassersloffgas, durch Einwirkung verdünnter Schwefelsäure oder Salzsäure auf käufliches Zink bereitet, hat stets einen schwachen unangenehmen Geruch, welcher bekanntlich auf der Anwesenheit einer kleinen Menge eines flüssigen, der unreinen Naphta in den Eigenschaften nahe kommenden Kohlenwasserstoffs beruht. Das mittelst Schmiedeeisen bereitete Wasserstoffgas riecht noch unangenehmer, wegen des grölseren Gehalls an einem solchen Kohlenwasserstoff und auch wegen der darin enthallenen Spuren von Schwefelwasserstoff, Phosphorwasserstoff und manchmal Arsenwasserstoff. So unangenehm ist dieser Geruch, dals Wasserstoffgas nur sehr selten mit Schmiedeeisen bereitet wird, und fast nie mit Gulseisen, das ein noch unreineres Gas giebt, obgleich Schmiedeeisen und Gulseisen bei weitem wohlfeilere 